\title{
Genetic analysis of clinical mastitis in different risk periods by linear and threshold models
}

\author{
Enyew Negussie, Ismo Strandén and Esa Mäntysaari \\ MTT Animal Production Research, 31600, Jokioinen, enyew.negussie@mtt.fi
}

\section{Summary}

Understanding the genetic basis of clinical mastitis (CM) during lactation is essential in deciding on the best measure of $\mathrm{CM}$ for breeding value evaluation. $\mathrm{CM}$ is one of the leading reasons for premature disposal of dairy cows. Culled cows have incomplete lactation records, and in statistical analysis this may cause sampling biases, because culled cows are seldom a random sample. It is, therefore, essential to study the effects of culling information on the genetic analysis of CM. The objectives of this study were first: to estimate heritability and genetic association between $\mathrm{CM}$ during the different stages of first lactation using linear and threshold models, second: to assess the effects culling information on the estimates of variance (co)variance components and associated genetic parameters.

First lactation was divided into six lactation stages (risk periods) by days (d) after calving: CM1, (-7 to $150 \mathrm{~d})$; CM2, (-30 to $30 \mathrm{~d})$; CM3, (-30 to $150 \mathrm{~d})$; CM4, (31 to $150 \mathrm{~d})$; CM5, (150 to $300 \mathrm{~d})$; CM6, (-30 to $300 \mathrm{~d}$ ). To assess the effect of including or excluding records of cows that had been culled from the herd before the end of the risk period, two data sets were prepared. In the first data set (Data I), records of cows culled before the end of the risk period were not included. In the second data set (Data II), records of cows culled during the risk period were included; if the cow had been culled for mastitis reasons or had completed two-thirds of the opportunity period if culled for other reasons. Variance (co)variance components were estimated by linear and threshold-liability models employing Bayesian approach.

Heritability estimates using the linear model ranged from 0.005 to 0.024 for Data I, and from 0.005 to 0.029 for Data II, depending on the stages of lactation or risk period defined. The corresponding estimates from the threshold-liability model ranged from 0.034 to 0.076 , and from 0.043 to 0.083 for Data I and Data II, respectively. In general, increased sire variance and higher heritability were observed with the inclusion of culling information. Estimated genetic correlations between the $\mathrm{CM}$ traits were medium to high, and ranged from 0.42 to 0.99 in Data I, and from 0.61 to 0.99 in Data II. Thus CM cannot be regarded the same trait in the course of lactation.

Results from the threshold analyses showed that the heritability of liability to $\mathrm{CM}$ was highest for CM2 and followed by CM6, CM3 and CM1 with estimates of $0.083,0.073,0.073$ and 0.072 , respectively. Estimates for CM4 and CM 5 were the lowest with heritability of 0.043 and 0.047 , respectively. The high heritability estimate for CM2 indicates that most genetic information is in early lactation. Thus, the best measure of $\mathrm{CM}$ would be to consider only cases in early lactation. However, as the genetic correlation between $\mathrm{CM}$ traits defined over the different risk periods were less than one, mastitis cannot be regarded as the same trait in the different parts of lactation. Thus, a multivariate model, treating mastitis in different stages of lactation as different traits, would be the best model for sire evaluation.

Key words: Mastitis, Dairy cattle, Bayesian analysis, Genetic parameters 


\section{Introduction}

Mastitis is one of the most common and costly diseases in dairy cattle. It is also the leading reason for premature disposal of Finnish Ayrshire cows. Of the total Finnish Ayrshire cows culled in 2003, almost $22 \%$ were culled due to mastitis reasons. Apart from its effect on milk production, the high cost of culling due to mastitis comes from increased cost of replacement heifers. Besides, culled cows have incomplete lactation records or, statistically speaking missing data (Little and Robin 1987; Im et al. 1989). Including or excluding records of culled cows in statistical analysis may cause data sampling biases, since culled cows are seldom a random sample. Thus, it is essential to study the effects of culling information on the genetic analysis of clinical mastitis.

Clinical mastitis (CM) occurs unevenly along the lactation trajectory (Koivula et al. 2004). Around half of CM cases occur very early in lactation, and the rest of the cases are distributed over the remainder of lactation. However, for various reasons the incidences of CM occur at different stages of the lactation. For instance, in the beginning of lactation, many incidences will be due to the physiological stresses of calving and the rapid increase in milk yield (Lund et al. 1999). In later parts, most cases are probably caused by physical damage to the teats. An understanding of the incidences of $\mathrm{CM}$ during different lactation stages (risk periods) is essential in order to decide on the best measure of CM when estimating variance components or predicting breeding values. The objectives of this study were first: estimate heritability and genetic association between $\mathrm{CM}$ during the different risk periods using linear and threshold models, second: assess the effects of culling information on the estimates of (co)variance components and associated genetic parameters.

\section{Material and Methods}

Data were extracted from the Finnish health-recoding database. There were more than 112000 first lactation Ayrshire cows calving from 1992 to 2002. The cows were selected from herds that are actively participating in the health-recording scheme. Only first crop daughters (i.e. difference between the birth year of a daughter and that of her sire was smaller than 6 years) were included. Additional requirements were: a sire should have at least 20 daughters in the analysis, and the age at first calving should be between 23 and 30 months. The pedigree file had 1226 males, of which 979 sires had daughters in the data.

The whole first lactation was divided into six-periods by days (d) after calving as follows: CM1, (-7 to $150 \mathrm{~d})$; CM2, (-30 to $30 \mathrm{~d})$; CM3, (-30 to $150 \mathrm{~d})$; CM4, (31 to $150 \mathrm{~d})$; CM5, (150 to $300 \mathrm{~d})$; CM6, (-30 to $300 \mathrm{~d})$. In order to assess the effects of records from cows that had been culled from the herd before the end of the risk period, two data sets were prepared. In the first data set, records of cows culled before the end of the risk period were not included. Whereas in the second data set, records of cows culled during the risk period were included if the cow had been culled for mastitis reasons. Furthermore, records of cows that had been culled for reasons other than mastitis were also included provided that they had completed at least two-thirds of the opportunity period.

For each cow, CM was defined as a binary trait with " 0 " or " 1 " based on whether or not a cow had at least one veterinary treatment or diagnosis due to udder diseases and/or culled from the herd because of mastitis during the period of risk. For clinical mastitis, $\mathrm{CM}=0$, if a cow had not been treated or had not left the herd due to mastitis during the risk period, and $\mathrm{CM}=1$, if cow had been treated for mastitis or culled from the herd due to mastitis in the period of the risk. Detailed descriptions of the two data sets are in Table 1.

\section{Statistical model}

Threshold and linear sire models were used to estimate variance (co)variance components and associated genetic parameters. Heritabilities for the six clinical mastitis traits were estimated from univariate analyses while genetic correlations were estimated from bivariate and trivariate analyses. The model had fixed effects of age at calving, calving year-month, and the random effects of herd-3-year, sire and residual effects.

\section{Bayesian analysis}

Threshold-liability model (Gianola 1982) was used for the analysis of CM traits. For the binary variable CM, the model uses the threshold concept (Dempster and Lerner 1950; Falconer 1981), where an 
underlying continuous variable, liability $(\lambda)$ is assumed. Thus, the observed binary variable takes a value of 1 if $\lambda$ is larger than a fixed threshold and 0 otherwise. With the binary data, the threshold and the residual variance are not identifiable; therefore, these parameters were set to 0 and 1 , respectively.

Table 1. Number of records ( $N)$ and percentage of clinical mastitis cases (CM-\%) during the different risk periods in data sets without (Data I) ${ }^{\dagger}$ and with (Data II) culling information

\begin{tabular}{lcccc}
\hline \multirow{2}{*}{$\begin{array}{l}\text { Clinical mastitis traits } \\
\text { (days after calving) }\end{array}$} & No. & CM-\% & No. & CM-\% \\
\cline { 2 - 5 } & & & & \\
CM1 $(-7-150)$ & 112568 & 8.41 & 111256 & 8.89 \\
CM2 $(-30-30)$ & 112568 & 6.28 & 112554 & 6.28 \\
CM3 (-30 - 150) & 112568 & 8.50 & 111256 & 9.03 \\
CM4 (31 - 150) & 112568 & 2.50 & 111254 & 2.98 \\
CM5 $(151-300)$ & 112568 & 2.50 & 105094 & 4.36 \\
CM6 (-30 - 300) & 112568 & 10.5 & 105096 & 12.88 \\
\hline
\end{tabular}

tData I: Information on cows culled from the herd due to mastitis or any other reasons during the risk period was not included in the data. $¥$ Data II: Information on cows culled from the herd due to mastitis or any other reasons during the risk period was included in the data

For the genetic analysis of $\mathrm{CM}$ traits defined over the different risk periods, a Bayesian approach using Markov chain Monte Carlo (MCMC) methods (Korsgaard et al. 2003) was used. In matrix notation the general linear model is:

$$
\boldsymbol{\lambda}=\mathbf{X} \boldsymbol{\beta}+\mathbf{X}_{h} \mathbf{h}+\mathbf{Z}_{s} \mathbf{s}+\boldsymbol{\varepsilon}
$$

Where

$\begin{array}{ll}\boldsymbol{\lambda} & \text { is unobserved liabilities to CM } \\ \boldsymbol{\beta} & \text { is vector of fixed effects } \\ \mathbf{h} & \text { is vector of herd-3-year of calving effects } \\ \mathbf{s} & \text { is vector of sire genetic effects } \\ \boldsymbol{\varepsilon} & \text { is vector of residual effects }\end{array}$

$\mathbf{X}, \mathbf{X}_{\mathrm{h}}$ and $\mathbf{Z}_{\mathrm{s}}$ are incidence matrices that link appropriate effects in vectors $\boldsymbol{\beta}, \mathbf{h}$, and $\mathbf{s}$ to the liabilities to CM.

The fixed effects in $\boldsymbol{\beta}$ were age at first calving and calving month-calving year. Age at first calving and calving month-calving year effects had 8 and 36 classes, respectively. The data from 1992-2002 was divided into four 3-year periods (1992-1994; 1995-1997; 1998-2000; 2000-2002) in order to make classes for the herd-3-year effect. There were 8750 herds and 14384 herd-3-year periods. Herd-year effect was treated as random in order to avoid the extreme category problem (ECP). ECP arises when there is small number of records per herd; the prevalence is either high or low giving rise to the possibility that all observations fall in the same category, as either "1" or "0", exists. When this occurs, the maximum likelihood estimates of such herd effects, when treated as fixed, are not finite. Treating herd effects as random with null mean can remove biases in inferences about variance components (Moreno et al. 1997). As this doesn't always work well, Rekaya et al. (2000) suggested assigning herd effects a normal prior with unknown mean.

\section{Prior distributions}

Independent uniform priors, $\mathrm{U}(-99,99)$ were assigned to each of the elements of $\beta$. Multivariate normal prior distributions were assigned to the herd-3-year effects, $\mathbf{h} \sim \mathrm{N}\left(\mathbf{0}, \mathbf{H}_{\mathbf{0}} \otimes \mathbf{I}\right)$, and to the sire additive genetic effects, $\mathbf{s} \sim \mathrm{N}\left(\mathbf{0}, \mathbf{G}_{\mathbf{0}} \otimes \mathbf{A}\right)$. Here $\mathrm{H}_{0}$ and $\mathrm{G}_{0}$ are (co)variances of herd-3-year and sire effects, respectively, and $\mathbf{A}$ is the matrix of additive relationship between sires of order 1226. Inverse Wishart prior distribution were used for matrices $\mathbf{H}_{\mathbf{0}}$ and $\mathbf{G}_{\mathbf{0}}$ : $\mathbf{H}_{\mathbf{0}} \sim \operatorname{IW}\left(\mathrm{v}_{\mathrm{h}}, \mathbf{V}_{\mathrm{h}}\right)$ and $\mathbf{G}_{\mathbf{0}} \sim \operatorname{IW}\left(\mathrm{v}_{\mathrm{g}}, \mathbf{V}_{\mathrm{g}}\right)$, where $\mathrm{v}_{\mathrm{h}}$ and 
$\mathbf{V}_{\mathrm{g}}$ are the degrees of freedom parameters and $\mathbf{V}_{\mathrm{h}}$ and $\mathbf{V}_{\mathrm{g}}$ are scale matrices.

Convergence diagnostics

The Gibbs sampler was run as a single chain. Length of burn-in and of sampling period, and a measure of mixing rate were obtained following Raftery and Lewis (1992). The effective number of iterates was determined by the initial positive sequence estimation (Geyer 1992). Based on the above-mentioned diagnostics and on visual inspection of trace plots, a chain of 50000 iterations was run, after a burn-in of 5000 rounds. All post burn-in samples were kept for inference about posterior distributions.

\section{Linear model analysis}

Inferences regarding estimates of variance (co)variance components from the Bayesian analyses were compared with the linear model analyses of the same data sets using REML. In the linear model the binary nature of the CM traits is ignored. The general structure of the model is given above except that here $\lambda$ is a vector of observations of CM (i.e. " 0 " or " 1 ") on the observable scale. (Co) variance components were estimated using the AI-REML procedure in the DMU package (Madsen and Jensen 2002).

\section{Results and discussion \\ Genetic parameters \\ Heritability}

Heritability estimates using the linear model from Data I and Data II ranged from 0.005 to 0.024 and from 0.005 to 0.029 (Table 2), respectively, depending on the stages of lactation or the risk period defined. In both Data I and Data II, the lowest heritability estimates were for CM4 and CM5, reflecting the low incidence of CM. The highest estimates of heritablity were from CM6 with estimates 0.024 and 0.029 from Data I and II, respectively. Heritability estimates for CM 1, CM2 and CM3 were all about 0.023 from Data I, and 0.024 from Data II. A linear model analysis on Danish Red cows involving different risk periods also showed a slightly higher heritability estimate for the period from 10 days before to 300 days after calving compared to other risk periods (Lund et al. 1999). On the underlying liability scale, however, they found the highest heritability for the period going from 10 days before to 50 days after calving. It seems that most of the genetic variation in CM is in early lactation.

When heritability estimates from the two data sets were compared, estimates for CM1, CM2, CM3 from Data II were 5\% higher than those from Data I. These were CM traits, which have been defined over the risk periods covering the early lactation stages. However, for CM traits, which have been defined over the later lactation stages, the difference in heritability estimates between the two data sets was higher. For these periods, estimates of heritabilities from Data II were 14 to $25 \%$ higher than those from Data I (Table 2). This result can be expected because it is during the late period of lactation where most animals are disposed off the herd due to mastitis reasons. With the inclusion of culling information, increased sire variance and higher heritability of CM has also been reported from a study on first lactation Norwegian dairy cattle (Heringstad et al. 2001).

Table 2. Linear model estimates of heritabilities for clinical mastitis traits defined over the different opportunity periods in first lactation Finnish Ayrshire in Data $I^{\dagger}$ and Data II

\begin{tabular}{|c|c|c|c|c|c|c|}
\hline \multirow[t]{2}{*}{$\begin{array}{l}\text { Clinical mastitis traits } \\
\text { (days after calving) }\end{array}$} & \multicolumn{3}{|c|}{ Data I } & \multicolumn{3}{|c|}{ Data II } \\
\hline & $\sigma_{\mathrm{g}}^{2}$ & $\sigma_{\mathrm{e}}^{2}$ & $\mathrm{~h}^{2}$ & $\sigma_{\mathrm{g}}^{2}$ & $\sigma_{\mathrm{e}}^{2}$ & $\mathrm{~h}^{2}$ \\
\hline CM1 (-7 - 150) & 0.000416 & 0.071037 & 0.023 & 0.000458 & 0.075388 & 0.024 \\
\hline CM2 (-30 - 30) & 0.000306 & 0.054521 & 0.022 & 0.000307 & 0.054535 & 0.023 \\
\hline CM3 $(-30-150)$ & 0.000428 & 0.071916 & 0.023 & 0.000471 & 0.076258 & 0.024 \\
\hline CM4 (31 - 150) & 0.000033 & 0.023851 & 0.005 & 0.000053 & 0.028283 & 0.007 \\
\hline CM5 (151 - 300) & 0.000045 & 0.023878 & 0.007 & 0.000091 & 0.040237 & 0.009 \\
\hline CM6 (-30 - 300) & 0.000538 & 0.086505 & 0.024 & 0.000770 & 0.102921 & 0.029 \\
\hline
\end{tabular}

tData I: Information on cows culled from the herd due to mastitis or any other reasons during the risk period was not included in the data. $¥$ Data II: Information on cows culled from the herd due to mastitis or any other reasons during the risk period was included in the data 
In general, estimates of heritabilities from the threshold model were higher than those from the linear model (Table 3). Here also the estimates of heritabilities of liability to CM from Data II were higher than those from Data I. This reflects the effect of more information, as a result of more CM cases.

In the threshold model analyses, marked differences in the heritability of liability to CM from the different risk periods were observed. Of the different risk periods, the heritability of liability to CM was higher for CM2 (-30 to 30) with an estimates of 0.076 and 0.083 from data I and II, respectively. The higher estimates of heritability of liability to CM from CM2 (-30 to 30) indicate that most genetic variation is found in the early part of the lactation period. This coincides with the fact that about 50 to $60 \%$ of the incidences of CM in Finnish Ayrshire occur during the early lactation period going from 30 days before calving to 30 days after calving (Koivula et al. 2004). This could therefore be one of the indications that CM2 may be the best measure of CM for sire evaluation, because there is more variation between sires during this period. Since economic losses due to mastitis are larger in the beginning of lactation, selecting sires based on low mastitis probabilities during the early period of lactation would therefore be rational. Moreover, the lower heritability estimates for the longer risk periods (such as CM6) compared to CM2 suggests loss of information about genetic variation in $\mathrm{CM}$ when multiple infections are lumped into a single infection episode.

Table 3. Posterior means of heritability of liability to clinical mastitis traits defined over the different opportunity periods in first lactation Finnish Ayrshire in Data $I^{*}$ and Data II

\begin{tabular}{lcccccc}
\hline $\begin{array}{l}\text { Clinical mastitis traits } \\
\text { (days after calving) }\end{array}$ & \multicolumn{3}{c}{ Data I } & \multicolumn{3}{c}{ Data II } \\
& $\sigma_{\mathrm{g}}{ }^{2}$ & $\sigma_{\mathrm{e}}{ }^{2}$ & $\mathrm{~h}^{2}$ & $\sigma_{\mathrm{g}}{ }^{2}$ & $\sigma_{\mathrm{e}}{ }^{2}$ & $\mathrm{~h}^{2}$ \\
CM1 $(-7-150)$ & 0.016286 & 1 & 0.064 & 0.018499 & 1 & 0.072 \\
CM2 $(-30-30)$ & 0.019565 & 1 & 0.076 & 0.021422 & 1 & 0.083 \\
CM3 $(-30-150)$ & 0.016736 & 1 & 0.065 & 0.018807 & 1 & 0.073 \\
CM4 (31 - 150) & 0.008633 & 1 & 0.034 & 0.011080 & 1 & 0.043 \\
CM5 $(151-300)$ & 0.011939 & 1 & 0.042 & 0.010706 & 1 & 0.047 \\
CM6 (-30 - 300) & 0.015834 & 1 & 0.062 & 0.018669 & 1 & 0.073
\end{tabular}

${ }^{\dagger}$ Data I: Information on cows culled from the herd due to mastitis or any other reasons during the risk period was not included in the data. ${ }^{\star}$ Data II: Information on cows culled from the herd due to mastitis or any other reasons during the risk period was included in the data

Most of the reported heritability estimates of CM tend to vary depending on type of data and method of analysis. Estimates of heritability using linear model have ranged from 0.001 to 0.06 with most values falling within the interval of $0.02-0.03$ (Syväjärvi et al. 1986; Pösö and Mäntysaari 1996; Heringstad et al. 1997; Luttinen and Juga 1997). Other estimates for first lactation cows range from 0.02 to 0.06 (Rupp and Boichard 1999; Hansen et al. 2002; Lassen et al. 2003). Heritability estimates on the linear scale are, however, influenced by frequency level, and estimates from different studies are, therefore, not easily comparable (Emanuelson 1988; Heringstad et al. 2000). On the other hand, estimates from threshold models on the underlying scales are often higher and range from 0.06 to 0.12 (Simianer et al. 1991; Lund and Jensen 1996; Heringstad et al. 1997). A 2 to 5 times higher heritability estimates has been reported by Weller et al. (1988) for binary scored traits with threshold model than with those from a linear model. In general, estimates of the posterior mean heritability of liability to $\mathrm{CM}$ from our study lies within the range of the above mentioned studies.

\section{Genetic correlation among CM traits defined over the different risk periods}

Estimated genetic correlations between the CM traits were slightly higher for Data II than for Data I (Tables 4 and 5). This indicates the effects of better data capturing more genetic information on CM. Estimates from Data I range from 0.42 to 0.99 (Table 4) while those from data II range from 0.61 to 0.99 (Table 5). The moderate to high genetic correlations between clinical mastitis traits defined over the different risk periods suggest that clinical mastitis is a changing trait in the course of lactation, which is probably due to different genes operating at the different parts of lactation. There are only few studies that have considered CM during different risk periods. However, using a linear sire model, Lund et al. (1999) found that the genetic correlation between clinical mastitis in early lactation (-10 to 50 days after first 
calving) versus other periods ranged from 0.68 to 0.89 in Danish Red cows. In contrast, Emanuelson et al. (1988) found a negative genetic correlation between the periods of -10 to 150 days from parturition and 150 days after calving in Swedish Red cattle. Heringstad et al. (2003) found moderate to high genetic correlations using a longitudinal threshold model up to 270 days in milk for first-lactation Norwegian dairy cattle.

Table 4. Estimates of genetic correlations and standard errors (SE) between clinical mastitis traits defined over the different opportunity periods in first lactation Finnish Ayrshire in Data I"

\begin{tabular}{lcccccc}
\hline $\begin{array}{l}\text { Clinical mastitis } \\
\text { traits (days after } \\
\text { calving) }\end{array}$ & $\begin{array}{c}\text { CM1 } \\
(-7-150)\end{array}$ & $\begin{array}{c}\text { CM2 } \\
(-30-30)\end{array}$ & $\begin{array}{c}\text { CM3 } \\
(-30-150)\end{array}$ & $\begin{array}{c}\text { CM4 } \\
(31-150)\end{array}$ & $\begin{array}{c}\text { CM5 } \\
(151-300)\end{array}$ & $\begin{array}{c}\text { CM6 } \\
(-30-300)\end{array}$ \\
\hline CM1 $(-7-150)$ & & & & & & \\
CM2 $(-30-30)$ & $0.97_{(0.011)}$ & & & & & \\
CM3 $(-30-150)$ & $0.99_{(0.001)}$ & $0.98_{(0.009)}$ & & & & \\
CM4 (31-150) & $0.95_{(0.065)}$ & $0.87_{(0.126)}$ & $0.94_{(0.072)}$ & & & \\
CM5 (151-300) & $0.57_{(0.116)}$ & $0.42_{(0.128)}$ & $0.57_{(0.115)}$ & $0.91_{(0.126)}$ & & \\
CM6 (-30-300) & $0.98_{(0.006)}$ & $0.93_{(0.020)}$ & $0.98_{(0.006)}$ & $0.99_{(0.066)}$ & $0.68_{(0.085)}$ & \\
\hline
\end{tabular}

tData I: Information on cows culled from the herd due to mastitis or any other reasons during the risk period was not included in the data

Table 5. Estimates of genetic correlations and standard errors (SE) between clinical mastitis traits defined over the different opportunity periods in first lactation Finnish Ayrshire in Data II ${ }^{\star}$

\begin{tabular}{|c|c|c|c|c|c|c|}
\hline $\begin{array}{l}\text { Clinical mastitis } \\
\text { traits (days after } \\
\text { calving) }\end{array}$ & $\begin{array}{c}\text { CM1 } \\
(-7-150)\end{array}$ & $\begin{array}{c}\text { CM2 } \\
(-30-30)\end{array}$ & $\begin{array}{c}\text { CM3 } \\
(-30 \text { to } 150)\end{array}$ & $\begin{array}{c}\text { CM4 } \\
(31-150)\end{array}$ & $\begin{array}{c}\text { CM5 } \\
(151-300) \\
\end{array}$ & $\begin{array}{c}\text { CM6 } \\
(-30-300)\end{array}$ \\
\hline CM1 (-7 - 150) & & & & & & \\
\hline CM2 (-30 - 30) & $0.97_{(0.014)}$ & & & & & \\
\hline CM3 $(-30-150)$ & $0.99_{(0.004)}$ & $0.97_{(0.012)}$ & & & & \\
\hline CM4 (31 - 150) & $\mathbf{0 . 9 6}_{(0.051)}$ & $0.84_{(0.120)}$ & $0.94_{(0.061)}$ & & & \\
\hline CM5 (151 - 300) & $\mathbf{0 . 7 5}(0.093)$ & $\mathbf{0 . 6 1}(0.114)$ & $\mathbf{0 . 7 5 _ { ( 0 . 0 9 3 ) }}$ & $\mathbf{0 . 9 4 _ { ( 0 . 0 8 8 ) }}$ & & \\
\hline CM6 (-30 - 300) & $0.98_{(0.008)}$ & $0.93_{(0.024)}$ & $0.98_{(0.008)}$ & $0.99_{(0.057)}$ & $\mathbf{0 . 8 3}(0.058)$ & \\
\hline
\end{tabular}

${ }^{\ddagger}$ Data II: Information on cows culled from the herd due to mastitis or any other reasons during the risk period was included in the data

\section{Conclusions}

Including culling information resulted in increased sire variance, heritability and slightly increased genetic correlations between the different CM traits, implying better data capturing more genetic information on $\mathrm{CM}$, especially for $\mathrm{CM}$ defined over the late lactation stages. Results from the threshold analyses showed that the posterior mean heritability of liability to CM was highest for CM2 (-30 to 30 days after calving) and followed by CM6 (-30 to 300d), CM3 (-30 to $150 \mathrm{~d}$ ) and CM1 (-7 to 150) with estimates of 0.083, $0.073,0.073$ and 0.072 , respectively. The high heritability estimate for CM2 trait ( -30 to 30 days after calving) indicates that most genetic information is in early lactation. Thus, the best measure of CM would be to consider only cases in early lactation. However, the genetic correlation between CM traits defined over the different risk periods were less than one, implying that mastitis cannot be regarded as the same trait in the different parts of lactation. Therefore, a multivariate model treating mastitis in different stages of lactation as different traits may be required for accurate genetic evaluation.

\section{References}

Dempster, E. R. and Lerner, I. M. 1950. Heritability of threshold characters. Genetics. 35:212-236

Emanuelson, U., Danell, B., Philipsson, J. 1988. Genetic parameters for clinical mastitis, somatic cell counts, and milk production estimated by multiple-trait restricted maximum likelihood. J. Dairy Sci. 71: 467-476

Falconer, D. S. 1981. Introduction to quantitative genetics, 340pp., Longman, New York.

Geyer, C.J. 1992. Practical Markov Chain Monte Carlo. Statistical Science. 7:473-511 
Gianola, D. 1982. Theory and analysis of threshold characters. J. Anim. Sci. 54:1079-1096.

Hansen, M., Lund, M. S., Sorensen, M. K. and Christensen, L. G. 2002. Genetic parameters of dairy character, protein yield, clinical mastitis, and other diseases in the Danish Holstein cattle. J. Dairy Sci. 85:445-452.

Heringstad, B., Karlsen, A., Klemetsdal, G., and Ruane, J. 1997. Preliminary results from the genetic analysis of clinical mastitis data. Interbull Bull. No. 15:45-49.

Heringstad , B., Klemetsdal, G. and Ruane, J. 2000. Selection for mastitis resistance in dairy cattle - A review with focus on the situation in the Nordic countries. Livest. Prod. Sci. 64:95-106.

Heringstad, B., Rekaya, R., Gianola, D., Klemetsdal, G. and Weigel, K. A. 2001. Bayesian analysis of liability to clinical mastitis in Norwegian cattle with a threshold model: Effects of data sampling method and model specification. J. Dairy Sci. 84:2337-2346.

Im, S., Fernando, R. L. and Gianola, D. 1989. Likelihood inferences in animal breeding under selection a missing-data theory view point. Genet. Sel. Evol. 21:399-414

Koivula, M., Mäntysaari, E. A., Negussie, E. and Serenius, T. 2005. Genetic and Phenotypic Relationships Among Milk Yield and Somatic Cell Count Before and After Clinical Mastitis J. Dairy Sci. 88:827-833.

Korsgaard, I. R., Lund, M. S. Sorensen, D., Gianola, D., Madsen, P. and Jensen, J. 2003. Multivariate Bayesian analysis of Gaussian, right censored Gaussian, ordered categorical and binary traits using Gibbs sampling. Genet. Sel. Evol. 35:159-183.

Lassen, J. Hansen, M, Sorensen, M. K., Pedersen, G. A., Christensen, L. G. and Madsen, P. 2003. Genetic relationships between body condition score, dairy character, mastitis, and diseases other than mastitis in first-parity Danish Holstein cows. J. Dairy Sci. 86:3730-3735.

Little, R.J.A. and Rubin, D.B. 1987. Statistical Analysis with Missing Data. Wiley, New York.

Lund, M.S. and Jensen, J. 1996. Bayesian estimation of genetic and phenotypic parameters for clinical mastitis, somatic cell production deviance and protein yield in dairy cattle using Gibbs sampling. 47th Annual Meeting of EAAP, Lillehammer, 7 pp.

Lund, M.S., Jensen, J. and Peterson, P. H. 1999. Estimation of genetic and phenotypic parameters for clinical mastitis, somatic cell production deviance, and protein yield in dairy cattle using Gibbs sampling. J. Dairy Sci. 82:1045-1051.

Luttinen, A. and Juga, J. 1997. Genetic relationships between milk yield, somatic cell count, mastitis, milkability and leakage in Finnish dairy cattle population. Proceedings of the international workshop on genetic improvement of functional traits in cattle; health. Uppsala, Sweden, June 1997. Interbull Bull. 15:78-83.

Madsen, P. and Jensen, J. 2002. A User's Guide to DMU. A package for analyzing multivariate mixed models. Version 6, release 4. Danish Institute of Agricultural Sciences, Denmark.

Moreno, C. Sorensen, D., Garcia-Cortes, L. A., Varona, L and Altarriba, J. 1997. On biased inferences about variance components in the binary threshold model. Genet. Sel. Evol. 29:145-160.

Pösö, J. and Mäntysaari, E. A. 1996. Relationships between clinical mastitis, somatic cell score, and production for the first three lactations of Finnish Ayrshire. J. Dairy Sci. 79:1284-1291.

Raftery, A. L. and Lewis, S. 1992. How many iterations in the Gibbs sampler? Pages 763-774 in Bayesian Statistics 4. J. M. Bernando, J. O. Berger, A. P. Dawid, and A.F.M. Smith ed. Oxford University Press, Oxford UK.

Simianer, H., Solbu, H. and Schaeffer, L. R. 1991. Estimated genetic correlations between disease and yield traits in dairy cattle. J. Dairy Sci. 74:4359-4365.

Rekaya, R., Weigel, K.A., Gianola, D., Heringstad, B. and Klemetsdal, G. 2000. Methods for attenuating bias of variance component estimates in threshold models when herds are small. J. Dairy Sci. 83(Suppl.1):56-57.

Rupp, R. and Boichard, D. 1999. Genetic parameters for clinical mastitis, somatic cell score, production, udder type traits, and milking ease in first-lactation Holsteins. J. Dairy Sci. 82:2198-2204.

Syväjärvi, J., Saloniemi, H. and Gröhn, Y. 1986. An epidemiological and genetic study on registered disease in Finnish Ayrshire cattle. Acta,. Vet. Scand. 27:223-234.

Weller, J. I, Saran, A. and Zeliger, Y. 1992. Genetic and environmental relationships among somatic cell count, bacterial infection and clinical mastitis. J. Dairy Sci. 75:2532-2540. 